\title{
Efficiency of vehicle operation in the context of digital transformation of transportation technologies
}

\author{
Denis Kochegura ${ }^{1 *}$ \\ ${ }^{1}$ Kuban State Technological University, Russia
}

\begin{abstract}
The paper describes the features of planning in-house technological, transport and logistics processes of a resource-extracting complex. The factors influencing the transport capacity of production processes and their situational analysis are given. The directions of optimization of related interrelated processes based on digital transformation of characteristic indicators and their step-by-step iteration are proposed
\end{abstract}

\section{Introduction}

One of the main productions and technological processes of the resource-producing complex and the oil-producing fields that are part of it is the current and capital repairs of existing oil wells.

In the course of the conducted scientific and applied research it was found that the plan for major repairs of existing oil wells is drawn up without taking into account the virtually unavoidable upcoming costs for transport support of this process and reducing them by lowering the mileage of technological transport vehicles when transporting a set of drilling and technological equipment from an operational well, after major repairs, to a well awaiting major repairs using the existing transport network of the resource-producing complex.

In addition, it was found that the volume of materials used and the amount of technological equipment for capital repairs of existing oil derricks may vary depending on the degree of impact of the following factors:

- f1 - weather states;

- f2 - hidden defects of the technological materials used;

- f3 - emergency failures of technological equipment;

- f4 - individual characteristics of wells included in the capital repair plan.

The influence of these factors changes the transport capacity of the work, planned major repairs, the volume of transportation in general for oil-producing locations and on certain sections of routes used for transporting a set of drilling equipment and technical equipment from well to well [1].

\footnotetext{
* Corresponding author: d.kochegura@mail.ru
} 


\section{Materials and methods}

The presence of these factors makes it necessary to adjust the routes of transportation of a set of drilling equipment and technical equipment, the content of the transported technological set and the choice of the most effective transport scheme.

Moreover, if the factor $\mathrm{fl}$ can be considered at the beginning of the transport service of the oil well repair process then the factors $\mathrm{f} 2, \mathrm{f} 3, \mathrm{f} 4$ are identified only during the well repair, each separately or in a certain combination: $\mathrm{f} 2+\mathrm{f} 3+\mathrm{f} 4 ; \mathrm{f} 2+\mathrm{f} 3 ; \mathrm{f} 3+\mathrm{f} 4 ; \mathrm{f} 2+\mathrm{f} 4$.

The influence of these factors changes the volume of transport work. But, if factors $f 2$ and $\mathrm{f} 3$ lead to an increase in transport work associated with the additional delivery of quantitative technological materials and the necessary components or aggregates to restore the operability of technological equipment, then factor $\mathrm{f} 4$ leads, as a rule, to the remnants of technological material after performing work at the well and the possibility of using the remaining volume for repairs at the another well, i.e., to a decrease in the transport work of technical transport vehicles [2].

Based on empirical data, it was found that out of 100 cycles of delivery of a set of drilling equipment and technical equipment to wells located within one oil field, for which 14,600 machine-hours were planned, the influence of factors was distributed as follows:

1. Situation $\mathrm{f} 2 \mathrm{f} 3-4.5 \%$ of machine shipments that caused repeated rides (machine hours);

2. Situation $\mathrm{f} 2-3.0 \%$ of machine shipments that caused repeated rides (machine hours);

3. Situation $\mathrm{f} 3-2.0 \%$ of machine shipments that caused repeated rides (machine hours);

4. Situation $\mathrm{f} 4-(-5.0) \%$ of machine shipments that caused repeated rides (machine hours);

5. Situation f2f3f $4-4.2 \%$ of machine shipments that caused repeated rides (machine hours);

6. Situation $\mathrm{f} 2 \mathrm{f} 4-3.5 \%$ of machine shipments that caused repeated rides (machine hours);

7. Situation $\mathrm{f} 3 \mathrm{f} 4-4.3 \%$ of machine shipments that caused repeated rides (machine hours).

From the above data, it can be observed that:

- with the simultaneous impact of all factors, the additional transport costs of machine hours increase by $4.2 \%$;

- factors $\mathrm{f} 2$ and $\mathrm{f} 3$ increase the labor intensity of transport services separately by $3.0 \%$ and $2.0 \%$, respectively, and in the sum of $\mathrm{f} 2 \mathrm{f} 3$ this increase is $4.5 \%$.

That is because their influence (local and cumulative) was shown on different rides included in the experiment format. Therefore, $\mathrm{f} 2 \mathrm{f} 3 \neq \mathrm{f} 2+\mathrm{f} 3$, since their consolidated effect was compensated by one repeated ride and not by separate ones.

- the greatest influence is provided by the factor $\mathrm{f} 4$ in a separate position and reduces the influence of other factors when they are present simultaneously. But in this case f $2 \mathrm{f} 3 \mathrm{f} 4$ $\neq \mathrm{f} 2 \mathrm{f} 3+\mathrm{f} 4$. This is due to the fact that $\mathrm{f} 4$ reduces the transport service capacity of the process of capital repairs of wells included in the experiment format.

Figures 1 and 2 illustrate the graphic content of the material presented. 


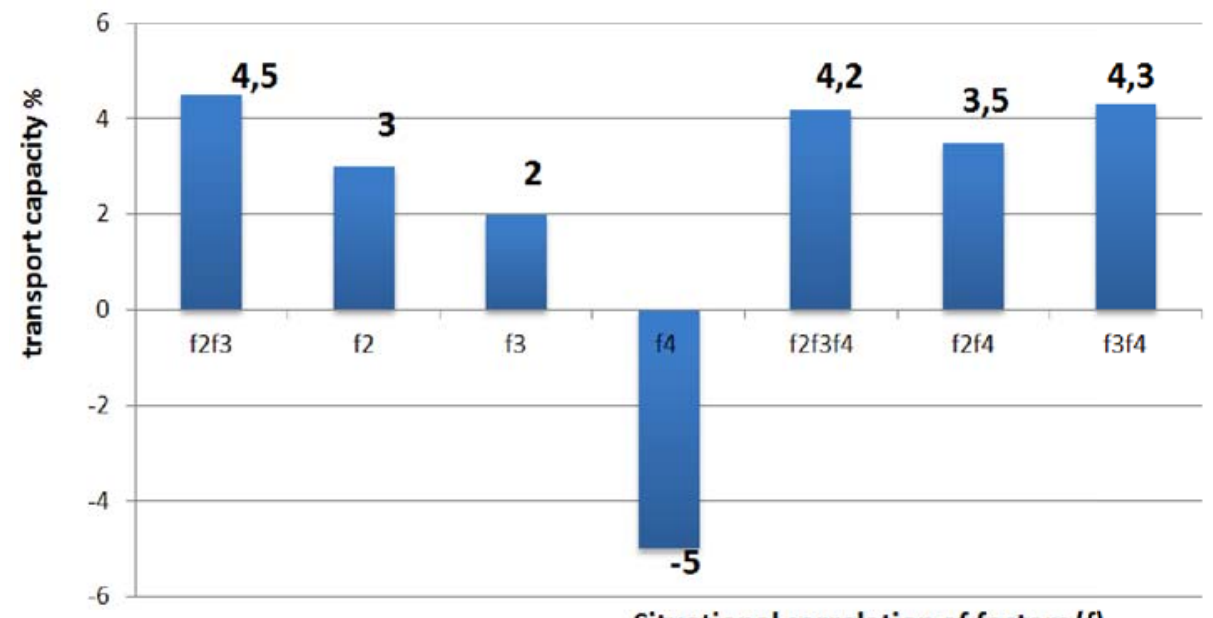

Situational correlation of factors (f)

Fig. 1. The percentage of changes in transport labor intensity in the presence of the main factors in various combinations.

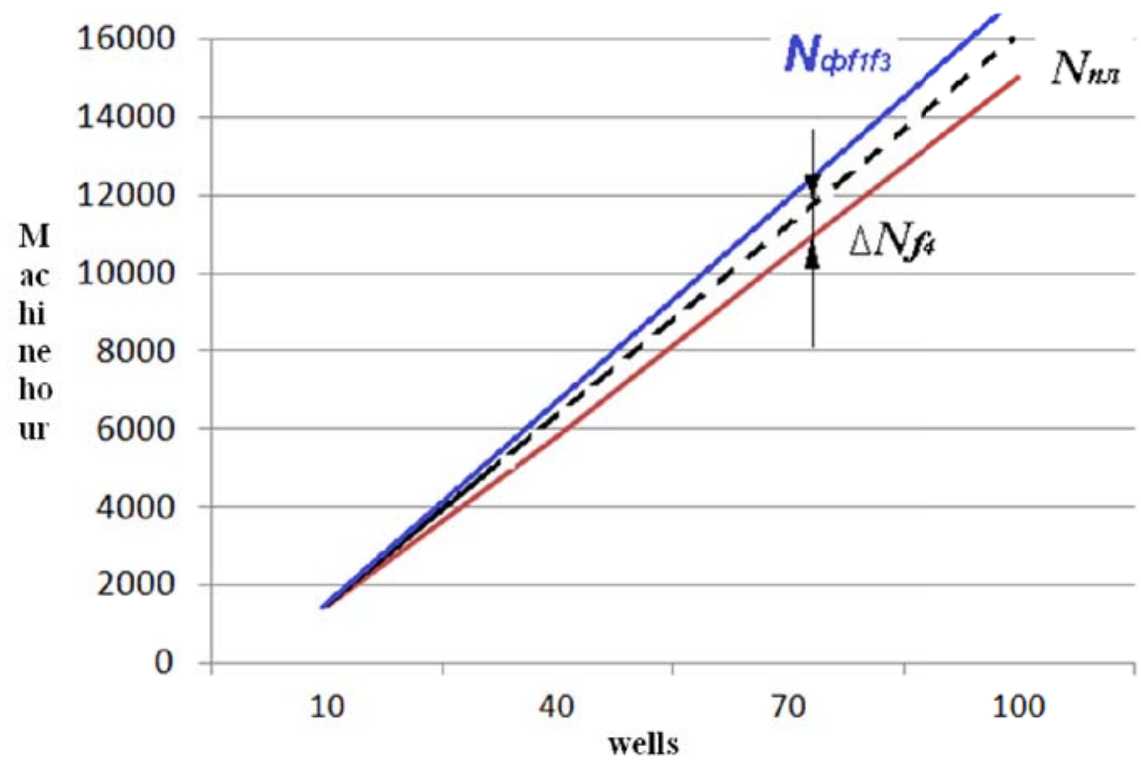

Fig. 2. The progress of planned rides during the transportation of a set of drilling equipment and technical equipment to the objects of planned capital repairs with increasing costs of machine hours of work. $\mathrm{Npr}$ - the performance of planned rides; $\mathrm{Nr}(\phi)$ - the real performance of rides in the presence of the combined influence of factors $\mathrm{f} 2 \mathrm{f} 3 ; \Delta \mathrm{Nf} 4$-the reserve of rides obtained from the local influence of factor $\mathrm{f} 4$.

The physical meaning of this phenomenon confirms the regularity of the obtained research results. It follows from the general theory of management that in order to eliminate deviations that occur in any technological process, the structural unit that makes decisions must have certain reserves that allow reducing their negative impact and developing a positive impact on the quality and efficiency of servicing the process of capital repairs of the resource-producing complex. [3] 
The results of the experiment indicate the need to improve the processes of planning major repairs of operating oil wells and its transport maintenance with minimal transport costs on the basis of digital transformation and comparability of their characteristic parameters.

To do this, it is necessary to assess the degree of coincidence (correlation) of the sequence of wells connected by a departmental (technological) transport network, united by a route network, but already compiled considering the minimization of transport costs (machine hours) and reducing the number of rides -with the sequence of the existing plan for major repairs of active oil wells. And the degree of correlation can be estimated by the presence of inconsistency in the performance of trips to scheduled wells and significant idle (unproductive) runs of technical transport vehicles. [4]

The route network of a resource-producing complex can be represented as a set of points Xi (objects included in the capital repair plan) connected by a transport network. Moreover, the transport network does not provide a direct connection "each to all and all to each" (Figure 3).

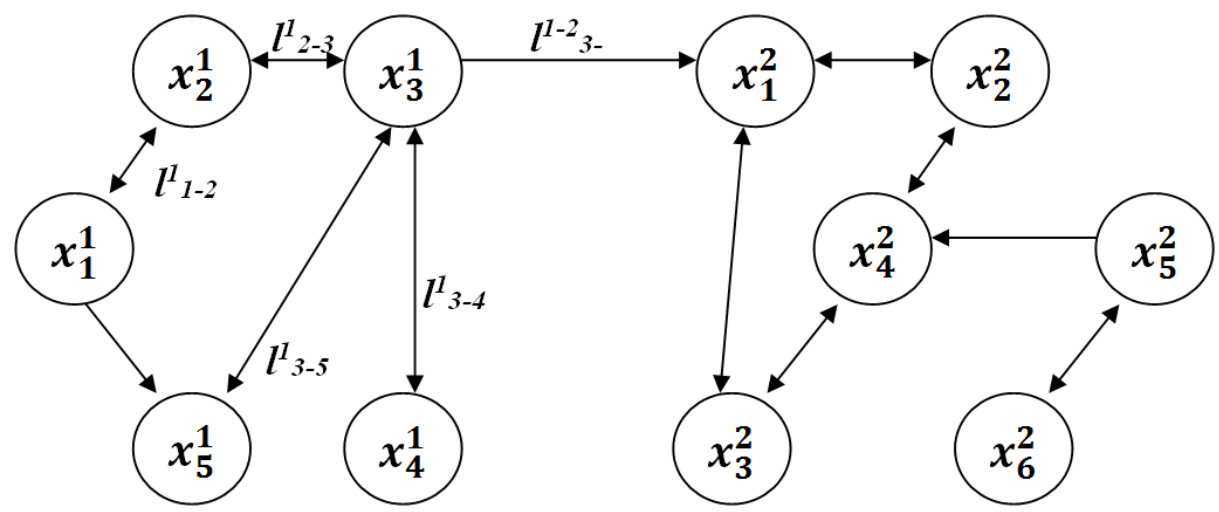

Fig. 3 Graphic illustration of the route network of the resource-producing complex. xki-i-th capital repair facility of the $\mathrm{k}$-th oil field:(i $\subset \mathrm{Ik}, \mathrm{k} \subset \mathrm{K})$; $11 \mathrm{i}-(\mathrm{i}+1)$ - the distance between adjacent capital repair facilities connected by a section of the departmental transport network; Ik - the total number of objects of capital repairs of the $\mathrm{k}$-th oil field; $\mathrm{K}$ - the total number of oil fields that are part of the resource-producing complex.

To create a rational transport scheme for cargo delivery to the objects of the capital repair plan for existing oil wells one can apply the Floyd algorithm using a sequence of $n$ iterations of the initial matrix. [5]

The solution of the above tasks makes it possible to draw up a technological diagram of their solution and the creation of a software product for use not only in the preparation of a plan for major repairs of existing oil wells and its transport services, i.e. at the level of planning production, technological, transport and logistics processes but also in the process of their interworking relationship, if there is an influence of unforeseen (accidental, hidden) and unaccounted factors.

\section{Conclusion}

Based on the presented material of the scientific and applied manual, the following conclusions can be made:

1. Planning of capital repairs of existing oil wells is carried out considering the upcoming and existing opportunities to reduce the cost of its transport maintenance. 
2. The established factors affecting the transport capacity of major repairs of existing oil wells and the situational analysis of their impact on the process of transport maintenance showed that their consideration can reduce the transport capacity of capital repairs of existing oil wells when changing the existing organizational method of its planning. [6]

3. Digital transformation of characteristic parameters and factors, used for step-by-step assessment of interrelated related production and technological capital repairs of operating oil wells and transport and logistics processes by iterating to the minimum transport costs, with full and timely transport support for the process of capital repairs of operating oil wells, makes it possible to optimize it and bring it closer to the optimal scheme of transport services. [7]

4. To create a rational and efficient transport scheme for servicing the transport space of the resource-mining complex when delivering cargo to the object, the Floyd algorithm can be applied using a sequence of $\mathrm{n}$ iterations of the initial matrix.

5. The presence of a technological step-by-step flowchart for preparing plans for major repairs of existing oil wells, organizing its transport services by mutual adjustment based on comparison, makes it possible to create a software product for operational use in practical work.

6. The outlined operations:

6.1. require changes in the organizational and technological scheme of preparing an application for transport services, the sequence of its consideration and making a final decision to ensure execution;

6.2. cause the need to make changes in the work of the organization's structures for planning and ensuring the interaction of production and technological, transport, logistics processes: major repairs of existing oil wells and its transport support.

\section{References}

1. Mirotin L.B., Lebedev D.U. Kochegura D.U., Digital transformation of the document flow of the production and technical service of the resource-producing complex. M.: Vestnik transporta, 4 - p. 34. (2020)

2. Kochegura D.U. Development of software for document management of the production and technical service in the "KNG-Kuban UTT", A collection of works of the winners of the XV Contest of scientific and technical developments among young people of enterprises and organizations of the fuel and energy complex - The Ministry of Industry and Energy of the Russian Federation, the Federal Agency for Energy - p. 124. (2007)

3. Lebedev E.A., Kochegura D.U., Vasiliev N.A. Improving the document flow of the production and technical service of the resource-producing complex, Electronic collection of scientific articles based on the materials of the second international scientific and practical conference of Kuban State Technological University 10 (2019).

4. Ju Y.J., Hou H.P., Yang J.L. Integration quality, value co-creation and resilience in logistics service supply chains: moderating role of digital technology // Industrial management \& data systems, Vol. 121. P. 364-380. (2020)

5. Joao Almeida Ana Dias Daniel Claudia Figueiredo. The future of management education: The role of entrepreneurship education and junior enterprises // The International Journal of Management Education. (2019)

6. Leila Afshari, Ali Hadian Nasab. Enhancing organizational learning capability through managing talent: mediation effect of intellectual capital // Human Resource Development International. (2021)

7. Choudhury A., Behl A., Sheorey P.A., Pal A. Digital supply chain to unlock new agility: a TISM approach // Benchmarking - an international journal. (2020) 